\section{Stress and Anxiety in Children After the Use of Computerized Dental Anesthesia}

Alexandra M. Queiroz ${ }^{1}$, Ariany B. Carvalho ${ }^{1}$, Laís L. Censi ${ }^{1}$, Carmen L. Cardoso², Christie R. Leite-Panissi ${ }^{3}$, Raquel Assed Bezerra da Silva', Fabricio Kitazono de Carvalho ${ }^{1}$, Paulo Nelson-Filho ${ }^{1}$, Lea Assed Bezerra da Silva ${ }^{1}$

\author{
'Department of Pediatric Dentistry, \\ School of Dentistry of Ribeirão \\ Preto, USP - Universidade de São \\ Paulo, Ribeirão Preto, SP, Brazil \\ ${ }^{2}$ Department of Psychology and \\ Education, School of Philosophy, \\ Sciences and Letters of Ribeirão \\ Preto, USP - Universidade de São \\ Paulo, Ribeirão Preto, SP, Brazil \\ ${ }^{3}$ Department of Morphology, \\ Phisiology and Basic Pathology, \\ School of Dentistry of Ribeirão \\ Preto, USP - Universidade de São \\ Paulo, Ribeirão Preto, SP, Brazil \\ Correspondence: Profa. Dra. \\ Raquel Assed Bezerra da Silva, \\ Avenida do Café s/n, Monte Alegre, \\ 14040-904 Ribeirão Preto, SP, \\ Brasil. Tel: +55-16-3315-0278. \\ e-mail: raquel@forp.usp.br
}

Key Words: children, cortisol, anxiety, stress, anesthesia.

\section{Introduction}

Despite the latest scientific and technologic advancements, dental treatment still is not agreeable and pleasant for most people, and visiting the dentist frequently generates a great deal of anxiety and stress to the patients (1).

Anxiety is a psychological and physiological state characterized by somatic, emotional, cognitive and behavioral components (2). The root meaning of the word anxiety is 'to vex or trouble'; either in the absence or presence of psychological stress, anxiety can develop feelings of fear, worry, uneasiness and dread (3). Anxiety is considered to be a normal reaction to a stressor. It may help a person to deal with a difficult situation by prompting one to cope with it. When anxiety becomes excessive, it may fall under the classification of an anxiety disorder (4). State-Trait Anxiety Inventory for Children (STAIC) is a selfreported anxiety instrument that measures trait (baseline) and state (situational) anxiety. Several studies $(5,6)$ used this instrument to assess self-reported anxiety as it can be considered the definitive method of anxiety measurement related to different situations or episodes in lifetime.

Stress may be defined as the sum of physical and mental responses resulting from the inability to distinguish the real facts from the personal experiences and expectations. It may be caused by anxiety and depression after an abrupt change in lifestyle or exposure to a certain environment, leading the person to feel afflicted and distressed. Stress has potential to disturb the normal functions of many systems of the human body, including the nervous, endocrine and immune systems (7). Therefore, it is important to resolve stress problems. Markers that show stress at an early stage will therefore be useful for diagnostic purposes. Researchers have attempted to establish methods to evaluate both pathological and physiological stress using biochemical markers, such as the concentrations of ACTH, catecholamine, galectin-1 prolactin, leptin, chromogranin $A$, and cortisol in the peripheral blood, saliva or urine (8-10).

Cortisol is secreted by the adrenal cortex. It regulates the metabolism of carbohydrates, proteins, fats and water, maintains the vascular reactions, regulates the sensitivity of the nervous system, regulates the number of blood cells and affects human response to stress (11). Measurement of salivary cortisol can be used to evaluate the stress of children during the dental treatment by collecting saliva samples by means of simple and stress-free procedures (12). Other reasons for choosing saliva over other biological fluids are that it reflects the responses to stress in a faster and more direct manner than urine, and it does not require invasive procedures such as blood collection (13). This is particularly interesting when evaluating young patients.

Dental fear and anxiety are frequently associated with the use of needles and syringes for local anesthesia. Painful perception during the administration of local anesthetics is often the main reason of anxious behaviors and defensive reactions and it may be caused by tissue puncture, 
pressure and velocity of fluid injection, temperature of the anesthetic and operator's tactile control of needle advance. The threatening appearance of dental syringes may also contribute to provoke or increase fear, especially in dentally anxious children (14). Fear/anxiety-related behavior has long been recognized as the most difficult aspect of patient management and can undermine an adequate dental care, especially in children.

Computer-controlled anesthetic delivery systems, such as The Wand ${ }^{\circledast}$ (Milestone Scientific Inc., Livingston, NJ, USA), have been developed in attempt to attenuate or overcome patients' fear and anxiety of local anesthesia required prior to invasive procedures. According to the manufacturer, The Wand ${ }^{\circledR}$ provides a precise injection flow rate and allows controlling the pressure exerted according to tissue resistance and density variations (15).

Several studies have compared conventional and computerized anesthesia in children and the results are contradictory. In some of these studies, local anesthesia with the computerized delivery system The Wand ${ }^{\varpi}$ was less painful and caused less anxiety than with conventional syringe injection $(16,17)$. Other authors, however, did not find significant differences between the techniques in order to reduce pain $(1,18)$ and anxiety $(19)$. However, in the majority of these studies, the conclusions were driven from different scoring scales that provided subjective assessments of children's pain, anxiety/stress, without using any objective parameter to evaluate the anesthetic techniques. Therefore, it would be interesting to evaluate children's perception of computer-controlled anesthetic delivery systems by using systemic markers, such as salivary cortisol levels, to determine their level of anxiety/stress.

In view of the above considerations, the aims of this study were to evaluate in children subjected to conventional and computerized (The Wand) anesthesia: 1 . The transitory stress levels by measurement of salivary cortisol; 2 . The anxiety state using a specific a psychological instrument.

\section{Material and Methods}

\section{Subjects}

The research protocol was approved by the Ethics Committee of the School of Dentistry of Ribeirão Preto, USP, Brazil (Process \#2009.1.198.58.7). Parental written informed consent was granted authorizing children's participation and publication of the results.

Twenty children of both sexes aged 7 to 12 years under treatment at the Pediatric Dentistry Clinic took part in this study. Children with congenital malformation, attending school classes not compatible with their age, diagnosed and treated neurological and/or psychological disorders, and hospitalization for health problems were excluded from the study. To be included in the study, the children should be in good general health and present at least two carious lesions with cavitation reaching dentine, located on the occlusal surface of homologous maxillary primary molars, requiring previous local anestesia, according to a randomized complete block design. During patient selection, in order to confirm the carious lesion depth, a radiographic examination was undertaken using Ultraspeed periapical films (Eastman Kodak Co. Rochester, NY, USA) size 0 or 2 according to the patient's age and an $\mathrm{x}$-ray unit operating at $70 \mathrm{kV}$ and $10 \mathrm{~mA}$ (Dabi Atlante Indústrias Médico Odontológicas Ltda., Ribeirão Preto, SP, Brazil) with a $0.6 \mathrm{~s}$ exposure time. A radiographic film holder was used to obtain standardized radiographic images. The radiographs were processed in an automatic film developer.

\section{Operative Procedures}

A single experienced pediatric dentist performed all local anesthetic procedures using either conventional syringe injection or computerized local delivery system (The Wand). The teeth of each child were randomly assigned to two groups ( $n=20 /$ group) by simple random sampling (draw): conventional or computerized local anesthesia. Before each local anesthetic injection, the mucosa on the site of needle puncture was air-dried and topical anesthetic (Benzotop 200mg/g - Benzocaine; DFL Indústria e Comércio, Rio de Janeiro, RJ, Brazil) was applied, slightly rubbed with a cotton mesh and left in contact for $3 \mathrm{~min}$. All patients received the same anesthetic solution (4\% articaine with epinephrine 1:100.000 - DFL, Rio de Janeiro, RJ Brazil). For standardization purposes, only infiltrative maxillary anesthesia was administered on the teeth to be treated and the entire content of an anesthetic cartridge $(1.8 \mathrm{~mL})$ was delivered. Usual behavioral control measures, namely communication and communicative guidance, tell-showdo, voice control, nonverbal communication, positive reinforcement and distraction, were used in all cases.

For the conventional local anesthesia, a Carpule syringe was used with a sterile disposable $30 \mathrm{G} 1$ needle. The mucosa was gently pulled for better visualization of the puncture site and infiltration started with minimum penetration of the needle and concomitant delivery of a small amount of anesthetic solution. The needle was advanced until reaching the desired depth and then the remaining anesthetic solution was slowly delivered with the least pressure possible.

The Wand ${ }^{\circledast}$ consists of a computer-controlled drive unit and a separate single-use disposable handpiece/needle assembly. The handpiece was attached to a conventional $1.8 \mathrm{~mL}$ anesthetic cartridge with plastic microtubing and a disposable needle. During the procedure, a microprocessor controlled the pressure of anesthetic injection while maintaining a constant flow rate. The amount of anesthetic 
to be injected was predetermined and controlled by the operator using a pedal. In this study, the device was programmed to maintain a slow flow, injecting one drop of solution every $2 \mathrm{~s}$.

Effectiveness of both anesthetic procedures was checked by pressing the anesthetized mucosa with a spatula. Instruments and/or equipment used in the procedures were not shown to children, unless they asked to see.

\section{Measurement of Salivary Cortisol Before and After Computerized and Conventional Anesthesia}

In order to investigate the hypothesis that the transitory stress levels in children, as measured by the dosage of cortisol released in the saliva, are lower after use of computerized anesthesia compared to conventional, one saliva sample was collected before and after each anesthetic technique in each patient. Saliva collection was performed in the morning because the physiological levels of cortisol are higher in this period.

The patients were instructed to wash the mouth with water 15 min before the first saliva collection. Immediately after the first saliva collection (S1) to determine the basal cortisol level, the children were anesthetized using either conventional or computerized anesthetic technique. The children were instructed to wash the mouth with water again to remove any fluids that could interfere with test results and the second saliva collection (S2) was done after $15 \mathrm{~min}$. Using a pipette, approximately $1 \mathrm{~mL}$ of saliva was collected in a $1.5 \mathrm{~mL}$ Eppendorff tube. The samples were identified and stored frozen at $-20{ }^{\circ} \mathrm{C}$. Salivary cortisol levels were dosed as described by Santiago et al. (20) and Castro et al. (21) by the radioimmunoassay technique and the results were expressed in $\mathrm{nmol} / \mathrm{L}$. The data were submitted to repeated-measures analysis of variance, comparing the individual differences of salivary cortisol levels obtained with both techniques ( $\alpha=0.05)$.

\section{Analysis of Anxiety Before and After Conventional and Computerized Anesthesia}

The children were evaluated individually before and immediately after each type of anesthesia by answering the State-Trait Anxiety Inventory for Children (STAIC), which is the most widely used self-report measure of anxiety in children. This psychological instrument was developed and validated by Spielberger et al. (21) and was translated into Portuguese and adapted to the Brazilian population by Biaggio (23). The STAIC consists of two separate, self-report 20-item scales, in which the children are asked to rate 20 statements for assessing two distinct anxiety concepts: a) the state-anxiety scale measures transitory anxiety states, which are subjective, consciously perceived feelings of tension, apprehension and worry that vary in intensity and fluctuate over time. This scale examines the shortterm state anxiety, which is specific to certain situations in a particular moment in time; b) the trait-anxiety scale measures relatively stable individual differences in proneness to anxiety, i.e., differences among children in the tendency to experience anxiety states. This scale examines how the children generally feel. The results of the STAIC were converted into numerical data for statistical analysis. In the present study, scores ranged from 20 to 60 .

The items on the state-anxiety scale of the STAIC were read to the children by a trained blinded psychologist and recorded the answers. Application of this instrument took approximately $10 \mathrm{~min}$.

With the numerical data stored in a databank, the variables were coded for statistical purposes. Data were analyzed statistically by the Mann-Whitney non-parametric test at $5 \%$ significance level.

\section{Results}

All patients attended both clinical appointments. The salivary cortisol levels increased in $8(40 \%)$ patients after conventional anesthesia and in $9(45 \%)$ patients after computerized anesthesia (Fig. 1), with no statistically significant difference $(p=0.3431)$ between the two types of anesthesia. In the same way, no statistically significant difference $(p=0.3948)$ was found between the techniques with respect to the psychological analysis based on the state-anxiety scale of the STAIC (Fig. 2).

\section{Discussion}

This study evaluated conventional and computerized (The Wand ${ }^{\otimes}$ ) anesthesia on the basis of the levels of stress/anxiety before and after the anesthetic procedures, as determined by the analysis of salivary cortisol and psychological assessment using the STAIC scale. No significant differences were found in the salivary cortisol levels or psychological assessment before and after conventional and computerized anesthesia in children aged 7 to 12 years. To the best of our knowledge, no previous studies have investigated salivary cortisol release before and after different types of dental local anesthesia, which hinders comparison of data. Nevertheless, considering the well known relationship between stress/anxiety and pain, it is possible to compare the results from this study with those of other studies that used different methodologies.

Overall, the studies comparing the conventional and computerized local anesthesia in children show conflicting results. The findings of the present study were similar to those of several authors $(1,18,19)$, while others found better results for computer-controlled anesthetic delivery systems $(16,17)$. All these studies compared the anesthetic techniques by analyzing exclusively ratings on 
pain and anxiety scales, which lead to subjectivity when it comes to scoring and interpretation, and possibly to misinterpretation of results, especially in children. In the present study, in addition to using the STAIC scale for psychological evaluation, the cortisol released in saliva before and after the procedures was also dosed for providing a quantitative measurement of a biochemical marker associated with the anxiety/stress level.

The fact that the site of needle puncture affects the painful sensation is widely known (1). For this reason, maxillary infiltrative anesthesia was performed in this study for standardization of the methodology. Additionally, all variables were randomly tested in all patients (each patient is his/her own control), thus minimizing the individual differences and biases in the study. In the literature, there are only 3 crossover studies comparing conventional and computerized anesthetic techniques delivered to the maxillary teeth of children. In one of these studies, The Wand system produced a significantly lower painful sensation (17). In the other two studies, no statistically significant differences were found between the techniques $(1,24)$, in the same way as observed in the present study. Recently, it was shown that palatal block technique with computerized injection was significantly less painful than conventional injection (VAS scale) in children. However, with time-consuming surgery, additional computerized analgesic solution had to be injected in the buccal gingiva when suturing, in some cases (25).

In the present study, the anesthetic procedures were performed by the same dentist and the non-pharmacological behavioral control measures and topical anesthesia were also standardized. Most children presented low levels of stress/anxiety after both types of anesthesia, which is in agreement with Ram and Peretz (24), who emphasized the importance of the dentist's skills and acquaintance with the anesthetic techniques as well as capacity of managing children's behavior during administration of local anesthesia.

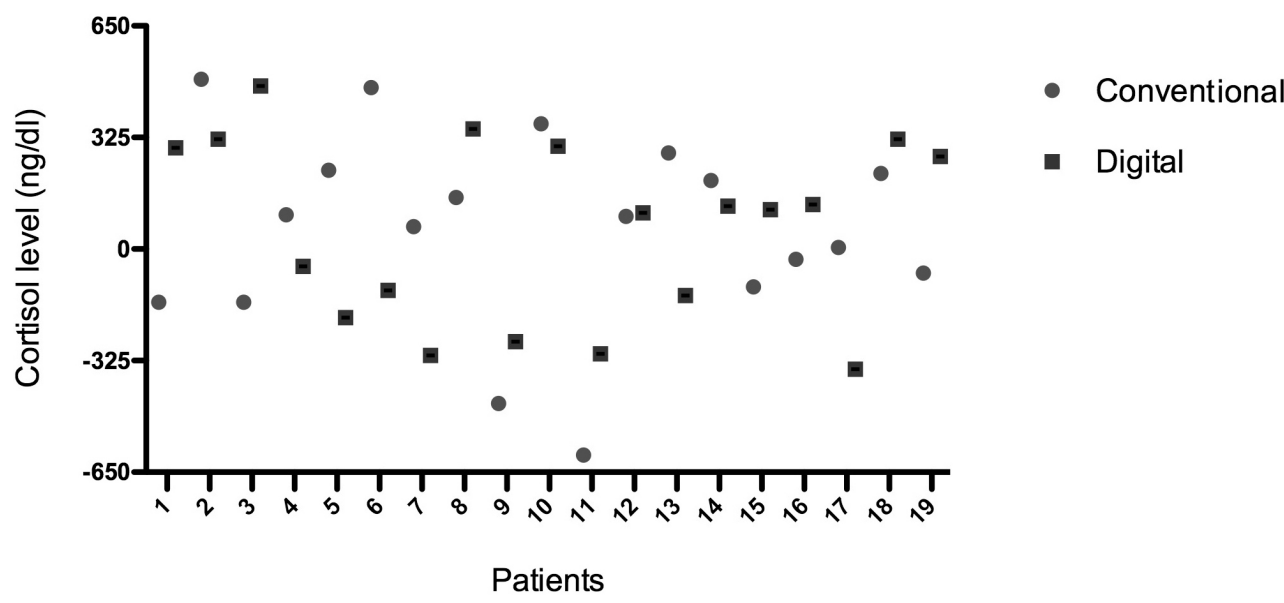

Figure 1. Salivary cortisol levels obtained before and after conventional and computerized anesthetic techniques.

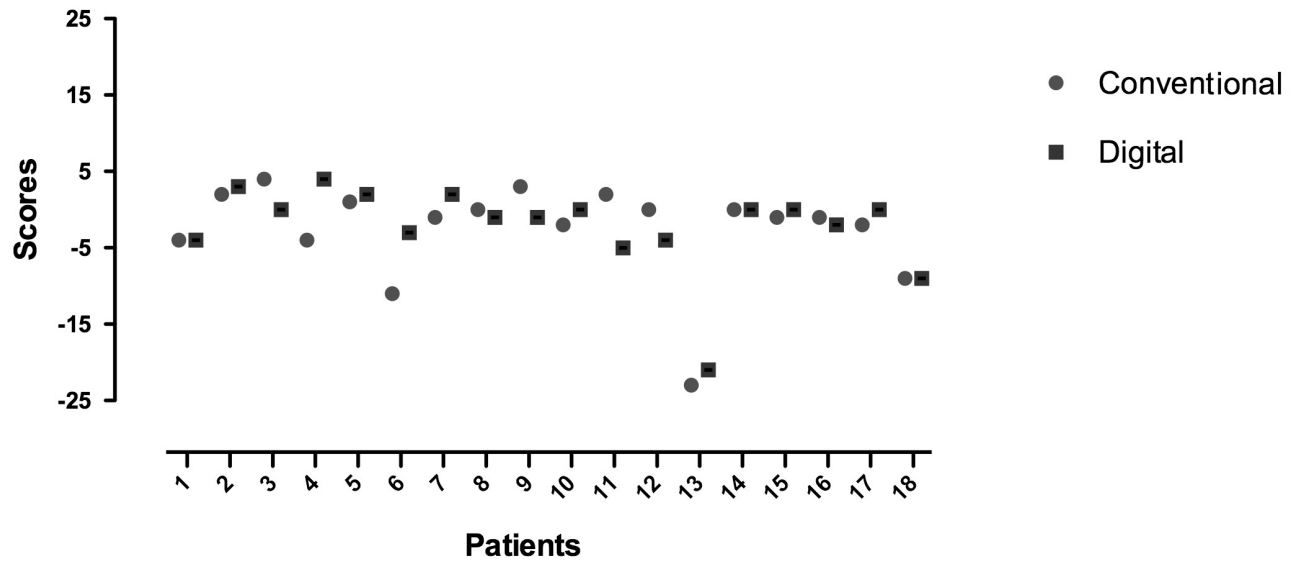

Figure 2. Psychological evaluation results obtained before and after conventional and computerized anesthetic techniques. 
In view of the obtained results, it may be concluded that local anesthesia using either conventional syringe injection or a computerized local delivery system (The Wand) produced similar level of stress/anxiety in pediatric patients, using both quantitative (salivary cortisol) and subjective (STAIC) analyses.

\section{Resumo}

0 objetivo deste estudo foi avaliar os niveis de estresse transitório e o estado de ansiedade em crianças submetidas à anestesia dental convencional e computadorizada. Vinte crianças (7 a 12 anos de idade) foram randomicamente designadas para receber anestesia dental convencional e computadorizada. Para investigar a hipótese que o estresse transitório poderia ser menor após a anestesia computadorizada, comparada à anestesia convencional, os niveis de cortisol na saliva foram medidos antes e depois de cada técnica. A ansiedade também foi avaliada individualmente por meio do State-Trait Anxiety Inventory for Children (STAIC). Os dados numéricos foram analisados estatisticamente pelo teste não paramétrico de Mann-Whitney (nivel de significância de 5\%). Os niveis salivares de cortisol aumentaram em $8(40 \%)$ pacientes após anestesia convencional e em 9 (45\%) pacientes após anestesia computadorizada, sem diferença estatisticamente significante entre os dois tipos $(p=0,34)$. Da mesma maneira, não foi encontrada diferença estatisticamente significante entre as técnicas $(p=0,39)$ com relação à análise psicológica baseada nos escores STAIC. Anestesia local usando tanto a anestesia convencional quanto o sistema de aplicação computadorizado produziu nivel similar de estresse/ansiedade em pacientes infantis, utilizando análises quantitativa e qualitativa.

\section{References}

1. Kuscu 00, Akyuz S. Is it the injection device or the anxiety experienced that causes pain during dental local anaesthesia? Int J Paediatr Dent 2008;18:139-145.

2. Seligman MEP, Walker EF, Rosenhan DL. Abnormal psychology. 4th ed. New York: W.W. Norton \& Company, Inc, 2001.

3. Bouras N, Holt G. Psychiatric and Behavioural Disorders in Intellectual and Developmental Disabilities. 2nd ed. Cambridge University Press: UK, 2007.

4. National Institute of Mental Health. Retrieved September 3, 2008.

5. Kim TK, Choi S, Shin YJ. Psychosocial factors influencing competency of children's statements on sexual trauma. Child Abuse Negl 2011;35:173179.

6. Perpina C, Cebolla A, Botella C, Lurbe E, Torro MI. Emotional eating scale for children and adolescents: psychometric characteristics in a Spanish sample. J Clin Child Adolesc Psychol 2011;40:424-433.

7. Eskandari F, Sternberg EM. Neural-301 immune interactions in health and disease. Ann NY Acad Sci 2002;966:20-27.

8. Ohashi $T$, Matsui $T$, Chujo M, Nagao M. Restraint stress upregulates expression of zinc transporter Zip14 mRNA in mouse liver. Cytotechnology 2008;57:181-185.

9. Torner L, Karg S, Blume A, Kandasamy M, Kuhn HG, Winkler J, et al.. Prolactin prevents chronic stress-induced decrease of adult hippocampal neurogenesis and promotes neuronal fate. J Neurosci 2009;29:1826-1833.

10. Bosch JA. The use of saliva markers in psychobiology: mechanisms and methods. Monogr Oral Sci 2014;24:99-108.

11. Ganong BR. Roles of lipid turnover in transmembrane signal transduction. Am J Med Sci 1991;302:304-312.

12. Hill $\mathrm{CM}$, Walker RV. Salivary cortisol determinations and self-rating scales in the assessment of stress in patients undergoing the extraction of wisdom teeth. Br Dent J 2001;191:513-515.

13. Okumura T, Nakajima Y, Matsuoka M, Takamatsu T. Study of salivary catecholamines using fully automated column-switching highperformance liquid chromatography. J Chromatogr B Biomed Sci Appl 1997;694:305-316.

14. Kuşcu 00, Akyuz S. Children's preferences concerning the physical appearance of dental injectors. J Dent Child 2006;73:116-121.

15. Wand Milestone Scientific. The Wand: Computer Controlled Anesthesia Delivery Sistem (handbook) 1998;1:27.

16. Oztas N, Ulusu T, Bodur H, Doğan C. The Wand in pulp therapy: an alternative to inferior alveolar nerve block. Quintessence Int 2005;36:559-564.

17. San Martin-Lopez AL, Garrigos-Esparza LD, Torre-Delgadillo G, Gordillo-Moscoso A, Hernandez-Sierra JF, Pozos-Guillen AJ. Clinical comparison of pain perception rates between computerized local anesthesia and conventional syringe in pediatric patients. J Clin Pediatr Dent 2005;29:239-243.

18. Koyuturk AE, Avsar A, Sumer M. Efficacy of dental practitioners in injection techniques: computerized device and traditional syringe. Quintessence Int 2009; 40:73-77.

19. Tahmassebi JF, Nikolaou M, Duggal MS. A comparison of pain and anxiety associated with the administration of maxillary local analgesia with Wand and conventional technique. Eur Arch Paediatr Dent 2009;10:77-82.

20. Santiago LB, Jorge SM, Moreira AC. Longitudinal evaluation of the development of salivary cortisol circadian rhythm in infancy. Clin Endocrinol 1996;44:157-161.

21. Castro M, Elias PCL, Quidute AR, Halah FPB, Moreira AC. Outpatient screening for Cushing's syndrome: the sensitivity of the combination of circadian rhythm and overnight dexamethasone suppresion salivary cortisol tests. J Clin Endocrinol Metab 1999;84:878-882.

22. Spielberg CD, Goursuch RL, Lushene RE. Manual for the STAI (Selfevaluation questionnaire). Consulting Psychologists Press: Palo Alto, California, 1970.

23. Biaggio AMB. Manual do Inventário de Ansiedade Traço-Estado para crianças (IDATE-C). 2a edição. Rio de Janeiro, RJ: CEPA 2002.

24. Ram D, Peretz B. The assessment of pain sensation during local anesthesia using a computerized local anesthesia (Wand) and a conventional syringe. J Dent Child 2003;70:130-133.

25. Jälevik B, Klingberg $G$. Pain sensation and injection techniques in maxillary dento-alveolar surgery procedures in children--a comparison between conventional and computerized injection techniques (The Wand). Swed Dent J 2014;38:67-75.

Received September 5, 2014 Accepted March 9, 2015 